\title{
A significant proportion of patients with chronic myeloid leukemia and suboptimal response according to European Leukemia Net criteria have excellent prognosis without treatment change
}

\author{
Peter Rohon ${ }^{\mathrm{a}}$, Edgar Fabera, Martina Divoka ${ }^{a}$, Sarka Rozmanova ${ }^{a}$, David Friedecky ${ }^{\mathrm{b}}$, Marie Jarosova ${ }^{\mathrm{a}}$, Karel Indrak ${ }^{\mathrm{a}}$
}

\begin{abstract}
Background. The Recommendations of the European Leukemia Net (ELN) have become an essential tool in the management and prognosis of patients with chronic myeloid leukemia (CML) treated with tyrosine kinase inhibitors (TKIs). However, the definition of suboptimal response remains under discussion.

Methods. We used conventional cytogenetics for the detection of clonal changes in Ph-positive and negative clones. RT-PCR and sequencing were carried out on peripheral blood leukocytes to detect the type of $B C R-A B L 1$ transcript. The $B C R-A B L 1$ mutational status was assessed using sequencing of RT-PCR products. High performance capillary electrophoresis for determination of imatinib (IMA) plasma concentration was used.

Results. A retrospective study of 110 patients diagnosed with chronic-phase (CP) CML treated with IMA or $2^{\text {nd }}$ generation TKIs in the years 2000-2009 focused on analysis of patients with suboptimal response according to ELN criteria. 40 patients were administered IMA as first-line therapy and 70 had been pretreated with interferon-alpha (IFN-a) with or without Ara-C and/or hydroxyurea (HU) for a median 12 months (range, 1-92 months). After adjusting for the ELN criteria, major molecular response (MMR) was achieved after median 34 and 39 months in $66.7 \%$ and $41.7 \%$ of patients after the first and second-line IMA therapy with suboptimal response defined as lack of achievement of MMR at the $18^{\text {th }}$ month of treatment, respectively. In comparison to patients with optimal response, patients with suboptimal response did not show significant differences in overall survival (OS) or progression-free survival (PFS). Cytogenetic assays demonstrated additional chromosome abnormalities (ACAs): chromosome 8 trisomy in a Ph-negative clone during the IMA treatment (in 1 case) and $\operatorname{der}(9 q)$ in Ph-positive clone (in 2 cases); in patients receiving first-line IMA only chromosome 8 trisomy was observed which was associated with myelodysplastic syndrome - this was the only case where hematopoietic stem cell transplantation (HSCT) was performed. During the treatment with IMA in both subgroups no regulatory mutations in the $A B L$ kinase domain were confirmed.

Conclusion. We believe that the category of suboptimal response should be redefined or withdrawn from the ELN 2009 recommendations for management of CML patients treated with TKIs. Patients with suboptimal response who have no additional risks (additional cytogenetic abnormalities or $B C R-A B L 1$ regulatory mutations) may remain on IMA treatment while patients with these risks should be switched to the $2^{\text {nd }}$ generation TKIs.
\end{abstract}

Key words: chronic myeloid leukemia, ELN recommendations, suboptimal response

Received: August 11, 2011; Accepted: October 24, 2011; Available online: November 30, 2011 http://dx.doi.org/10.5507/bp.2011.059

${ }^{a}$ Department of Hemato-Oncology, University Hospital Olomouc and Faculty of Medicine and Dentistry, Palacky University Olomouc, Czech Republic

${ }^{b}$ Laboratory of Inherited Metabolic Disorders, University Hospital Olomouc and Faculty of Medicine and Dentistry, Palacky University Olomouc

Corresponding author: Peter Rohon, e-mail:peter.rohon@centrum.cz

\section{INTRODUCTION}

The prognosis of patients with CML radically changed after 2000, when a completely new treatment with IMA entered clinical practice. The dramatically improved efficacy of IMA and later on, second generation TKIs necessitated the introduction of revised criteria for management and monitoring of CML patients. The Recommendations of the European Leukemia Net published first in 2006 and revised in 2009 gained very wide recognition and level of acceptance ${ }^{1,2}$. Response to treatment according to ELN criteria is divided into optimal, suboptimal and failure according to the achievement or failure to achieve CCyR and MMR at predefined time intervals (milestones).
While the definitions of optimal response and failure have shown clear prognostic value and implications for subsequent management of patients, the suboptimal response defined as failure to achieve CCyR at 12 months of treatment and MMR at 18 months recommended further treatment strategies that are more ambiguous: "suboptimal responders may continue on IMA, at the same or higher dose, or may be eligible for investigational therapy with $2^{\text {nd }}$ generation TKIs ${ }^{2 *}$. Also the prognostic significance of suboptimal response was found to be limited and has been questioned ${ }^{3}$.

In our retrospective study, we evaluated the significance of suboptimal response in two groups of patients with CP CML; first: 70 patients treated with second-line IMA 
(pretreated with IFN- $\alpha$ ) and second: 40 patients treated with IMA as front-line therapy. We approved the prognostic significance of suboptimal criteria according to ELN which is limited to event-free survival (EFS) only. We believe that the definition of suboptimal response should be revised and redefined or even withdrawn from ELN recommendations.

\section{MATERIAL AND METHODS}

\section{Patient's characteristics}

The analysis included all consecutive chronic-phase CML patients treated with first- or second-line IMA at the Department of Hemato-Oncology in Olomouc from $1^{\text {st }}$ December 2000 to $1^{\text {st }}$ May 2009. The group was analyzed as of $1^{\text {st }}$ March 2010. IMA was administered to 40 patients as first-line therapy (from September 2001) and as second-line therapy to 70 patients previously treated with IFN- $\alpha$ with or without Ara-C and/or HU (from November 2000).

\section{Treatment}

The patients were given a daily dose of $400 \mathrm{mg}$ of IMA. In cases of significant hematologic toxicity (National Cancer Institute grade III), treatment was rarely interrupted and intermittent dosage was mostly used ${ }^{4}$. In persistent neutropenia, G-CSF was administered in individual dosage regimens. Most patients had their plasma IMA levels monitored. If lower plasma IMA levels, suboptimal response or failure of therapy were noted, the drug dosage was individually increased to as much as $400 \mathrm{mg} /$ day or $2^{\text {nd }}$ generation TKIs were administered. In a minority of cases non-compliance was identified by the demonstration of lower plasma IMA levels.

\section{Definition of treatment response}

The ELN standard criteria were used (Table 1) (ref. $\left.{ }^{2}\right)$. Overall survival is defined as the interval from initiation of IMA therapy to the patient's death or the date of last analysis of the group ( $1^{\text {st }}$ March 2010); duration of IFN- $\alpha$ pretreatment is excluded from the analysis to ensure proper comparison of both groups. Progressionfree survival was also studied, with progression being de- fined according to the International Randomized Study of Interferon vs STI571 (IRIS) as acceleration, blast crisis, loss of complete hematologic response, loss of major cytogenetic response (MCyR), increasing white blood cell (WBC) count in patients who failed to achieve CHR and death. The last analyzed parameter was event-free survival, with an event being defined as progression, failure of IMA therapy (ELN), IMA intolerance and loss of CCyR, and failure to achieve MCyR by 12 months, MCyR by 18 months and CHR by 6 months of IMA therapy ${ }^{5}$.

\section{Statistical analysis}

For descriptive statistics, the following basic parameters were used: continuous variables - the median, arithmetic mean, range and standard deviation; categorical variables - the frequency. Survival analysis was performed using the Kaplan-Meier method. Survival curves were compared by the log-rank test. The Mann-Whitney $\mathrm{U}$ test served to compare parameters that showed other than normal distribution (e.g. leukocyte subpopulations). Normality of the distribution was verified by the Kolmogorov-Smirnov test. The results were referred to as statistically significant at the level of significance of $P<0.05$. All calculations were carried out using the SPSS software (version 15.0 for Windows, SPSS Inc., Chicago, USA).

\section{RESULTS}

\section{Basic characteristics}

A detailed description of the group is provided in (Table 2). From the whole group of 110 patients, 104 individuals were alive as of $1^{\text {st }}$ March 2010: in 5 cases, death resulted from progression of the disease and one patient died of a non-hematologic malignancy (laryngeal cancer).

The dosage of IMA in both first- and second-line therapy was standard (in $64.3 \%$ and $65.0 \%$ of patients, respectively) or increased to a maximum of $800 \mathrm{mg} /$ day (in $27.1 \%$ and $27.5 \%$ of patients, respectively) or reduced to a minimum of $100 \mathrm{mg} /$ day (in $8.6 \%$ and $7.5 \%$ of patients, respectively). In both subgroups, dosage was most commonly increased due to cytogenetic progression and reduced due to hematologic toxicity.

Table 1. ELN criteria for assessing treatment response in CP CML patients treated with IMA (ref. ${ }^{2}$ ).

\begin{tabular}{cccccc}
\hline Response & & \multicolumn{3}{c}{ Time of assessment (months) } \\
\hline Optimal & minCyR & PCyR & CCyR & MMR & Stable or improving MMR \\
Subopt. & No CyR & $<$ PCyR & PCyR & $<$ MMR & $\begin{array}{l}\text { Loss of MMR; BCR-ABL1 kinase domain } \\
\text { mutation sensitive to IMA }\end{array}$ \\
Failure & $<$ CHR & No CyR & $<$ PCyR & $<$ CCyR & $\begin{array}{l}\text { Loss of CHR; loss of CCyR; BCR-ABL1 ki- } \\
\text { nase domain mutation low sensitive to IMA, } \\
\text { ACAs in Ph-positive clone }\end{array}$ \\
\hline
\end{tabular}


Table 2. Basic characteristics of the patients.

\begin{tabular}{lcc}
\hline \multicolumn{1}{c}{ Parameter $^{\mathrm{a}}$} & $(\mathrm{IFN}-\alpha), 2^{\text {nd }}$ line IMA & $1^{\text {st }}$ line IMA \\
\hline No. of patients & $\mathrm{N}=70$ & $\mathrm{~N}=40$ \\
Sex (male/female) & $42 / 28$ & $24 / 16$ \\
Age at dg. (years) & $52(18-71)$ & $52(19-73)$ \\
Age at IMA start (years) & $56(24-75)$ & $52(19-73)$ \\
Duration of IFN- $\alpha$ therapy & $12(1-92)$ & - \\
Duration of IMA therapy & $64(7-103)$ & $41(3-81)$ \\
Follow-up (from dg.) & $85(4-236)$ & $43(4-101)$ \\
Sokal index (L/I/H) & $32 / 26 / 12$ & $16 / 11 / 13$ \\
Treatment: IMA failure & & $7 / 3$ \\
(dasatinib/nilotinib) & $7 / 4$ & $23 / 12 / 5$ \\
ELN criteria (O/S/F) & $22 / 24 / 24$ & \\
\hline
\end{tabular}

Legend: Sokal L/I/H - low/intermediate/high risk, ELN criteria (regardless of the time of assessment) O/S/F - optimal/suboptimal/failure, $\mathrm{N}$ - number of patients.

${ }^{a}$ Continuous variables are in the format of median (minimum-maximum) in months.

\section{Patient's survival}

The probability of 6-year survival was $95.4 \%$ in patients pretreated with IFN- $\alpha$ and $91.8 \%$ in first-line IMA therapy (this reflects the fact that deaths in this arm occurred within 15 months from the IMA start). The patients' survival was associated with the risk as expressed by ELN criteria. After adjustment by ELN criteria, statistically significantly better OS was seen in patients with optimal response (Fig. 1a, 1b). After 6-years follow-up, there was a statistically significantly lower ratio of progression in the optimal response subgroup (IFN- $\alpha$ pretreatment vs. first line IMA: optimal response $100 \%$ and $100 \%$, respectively; suboptimal response $100 \%$ and $91.7 \%$, respectively; failure $55.3 \%$ and $26.7 \%$, respectively; $P<0.0001$ and $P<0.0001$, respectively) (Fig. 2a, 2b). Similar results were also obtained for EFS: optimal response $95.5 \%$ and $94.7 \%$, respectively; suboptimal response $50.0 \%$ and $37.5 \%$, respectively; failure $0 \%$ and $0 \%$, respectively; $P<0.0001$ and $P<0.0001$, respectively) (Fig. 3a, 3b).

\section{ELN criteria (suboptimal response) vs. molecular response}

For an objective description of the treatment response achieved, the ELN criteria were used. We demonstrated that MMR was reached (IFN- $\alpha$ pretreatment vs. first line IMA): in 39 months (10 patients; $41.7 \%$ ) and in 34 months ( 8 patients; $66.7 \% ; P=0.10$ ). This clearly shows that there were no statistically significant differences in the achievement of MMR with respect to pretreatment with IFN- $\alpha$ and also that all patients from the suboptimal response subgroup reached the CCyR. Cytogenetic assays in patients pretreated with IFN- $\alpha$ demonstrated ACAs: chromosome 8 trisomy in a Ph-negative clone during the IMA treatment (in 1 case) and $\operatorname{der}(9 q)$ in $\mathrm{Ph}$ - positive clone (in 2 cases); in patients receiving first-line IMA only chromosome 8 trisomy was observed which was associated with the myelodysplastic syndrome - this was the only case where HSCT was performed. During the treatment with IMA in both subgroups no regulatory mutations in the ABL kinase domain were confirmed. We identified D276 mutation (in 2 cases) which is described as a silent mutation.

\section{DISCUSSION AND CONCLUSION}

Treatment responses in CML are defined according to hematologic, cytogenetic and molecular evaluations ${ }^{2,6}$. Milestones for suboptimal response and failure are different and several groups have developed guidelines defining inadequate response to IMA in patients with chronic phase CML based on failure to achieve specific levels of response within a defined duration of treatment ${ }^{7-9}$. We can estimate the rates of suboptimal response to IMA (defined by the ELN) using IRIS study data ${ }^{10}$. Using Kaplan-Meier curves for cumulative best response, approximately $88 \%$ of patients achieved CHR within 3 months, $69 \%$ achieved CCyR within 12 months and 62\% achieved MMR within 18 months (calculated in patients with a CCyR) (ref. ${ }^{11,12}$ ). It is important to note that response rates achieved at each time point are cumulative and do not reflect patients who subsequently lost their response before reaching the milestone.

Potential mechanisms behind suboptimal response to IMA therapy are likely to be multi-factorial. It is important to distinguish $B C R-A B L 1$-dependent and $B C R-A B L 1$-nondependent factors for understanding from a pathophysiological point of view; these factors may contribute jointly. 


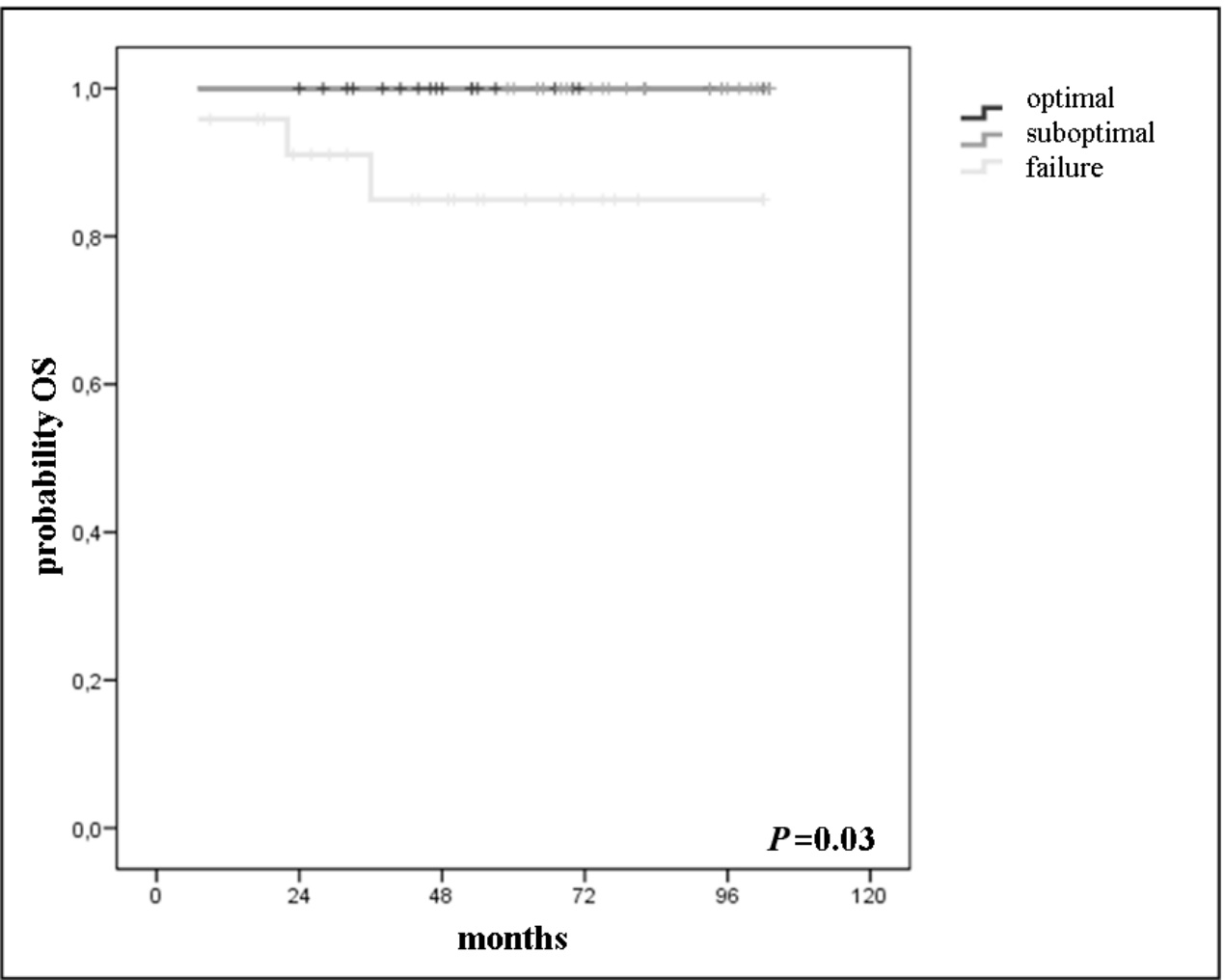

Fig. 1a. Overall survival in CML patients according to ELN criteria (IFN- $\alpha$ pretreatment).

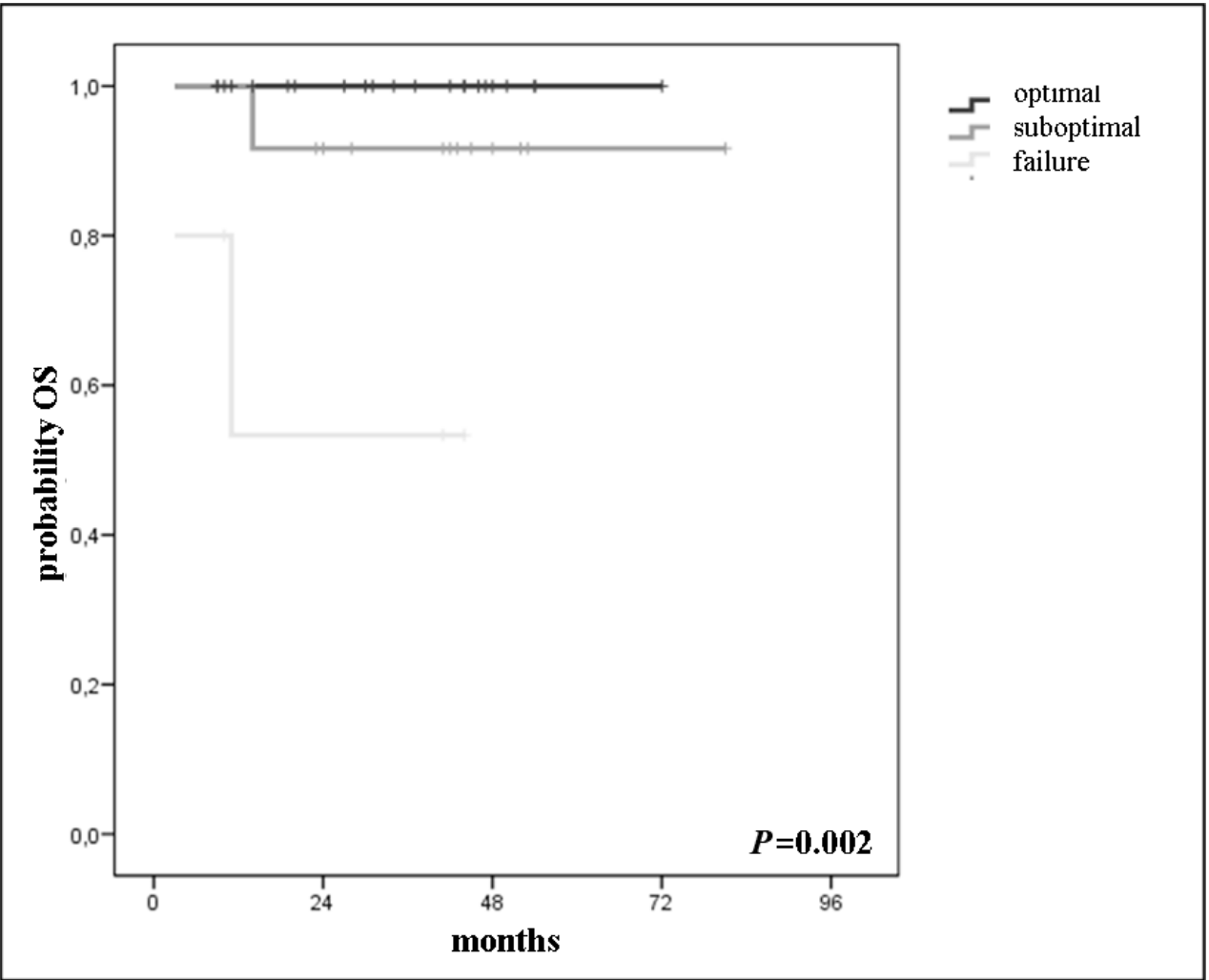

Fig. 1b. Overall survival in CML patients according to ELN criteria (IMA $1^{\text {st }}$ line therapy).

$B C R-A B L 1$-dependent mechanisms involve amplification of $B C R-A B L 1$ gene and point mutations in the segment which encodes the $B C R-A B L 1$ kinase domain. The nondependent mechanisms are associated with changes in extra- and intracellular levels of IMA and also with activation of other signaling pathways. The causes of resistance are summarized in (Table 3 ).

It seems that the categories, optimal and suboptimal response have in the case of OS and PFS a very similar stratification. Also pretreatment with IFN- $\alpha$ has not shown substantial impact for this parameter. Although the data are obtained from a relatively small group of patients, it clearly shows the inconsistency for classification into 3 different subgroups according to ELN criteria. Nevertheless, all patients with suboptimal response (assessed after 12 months) achieved CCyR and even a small 


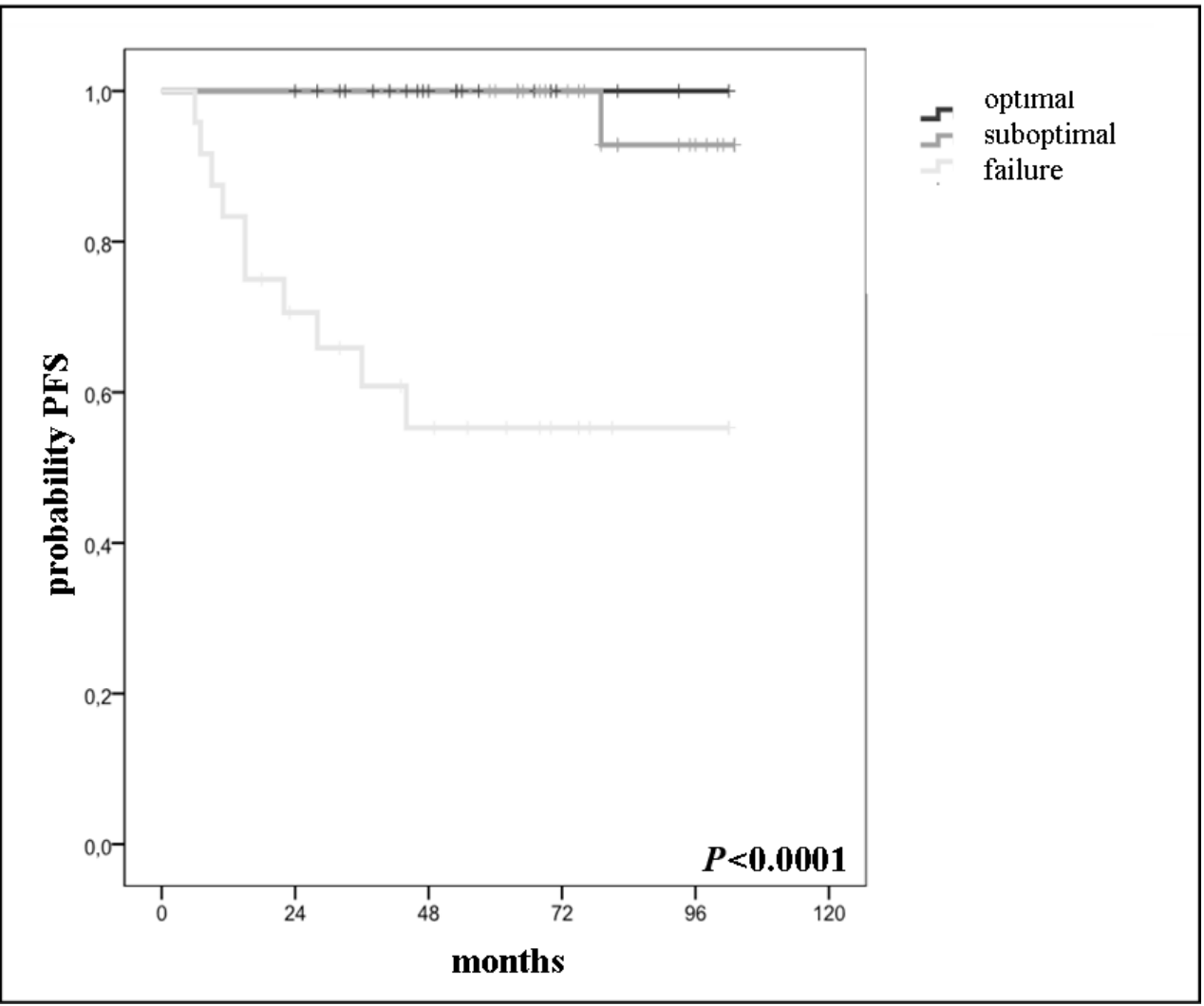

Fig. 2a. Progression-free survival in CML patients according to ELN criteria (IFN- $\alpha$ pretreatment).

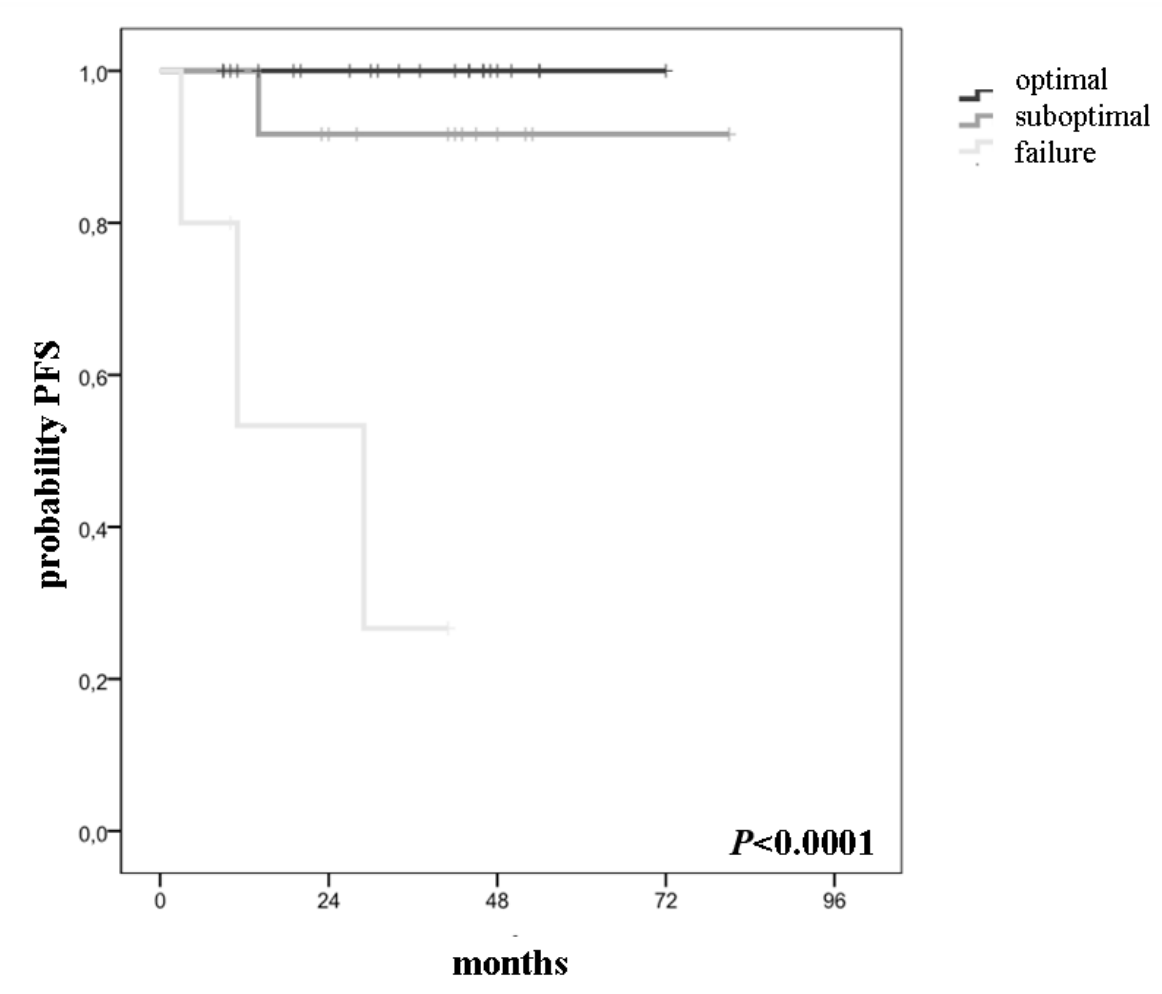

Fig. 2b. Progression-free survival in CML patients according to ELN criteria (IMA $1^{\text {st }}$ line therapy).

number of patients who failed on IMA treatment (did not achieve CCyR after 18 months) eventually reached CCyR. A different situation appears in the case of EFS; for this parameter the ELN criteria of 2009 are useful and have a predictive value.

Patients with suboptimal response clearly form a heterogenous group: a significant proportion of them show image characteristics which correspond to the optimal response. It is therefore necessary to define the crucial parameters in the suboptimal group with a prognostic value $^{25}$. According to the results of our retrospective analysis, we can certainly propose inclusion of the following criteria: the absence of ACA, the absence of mutations in the ABL kinase domain, improving molecular response 


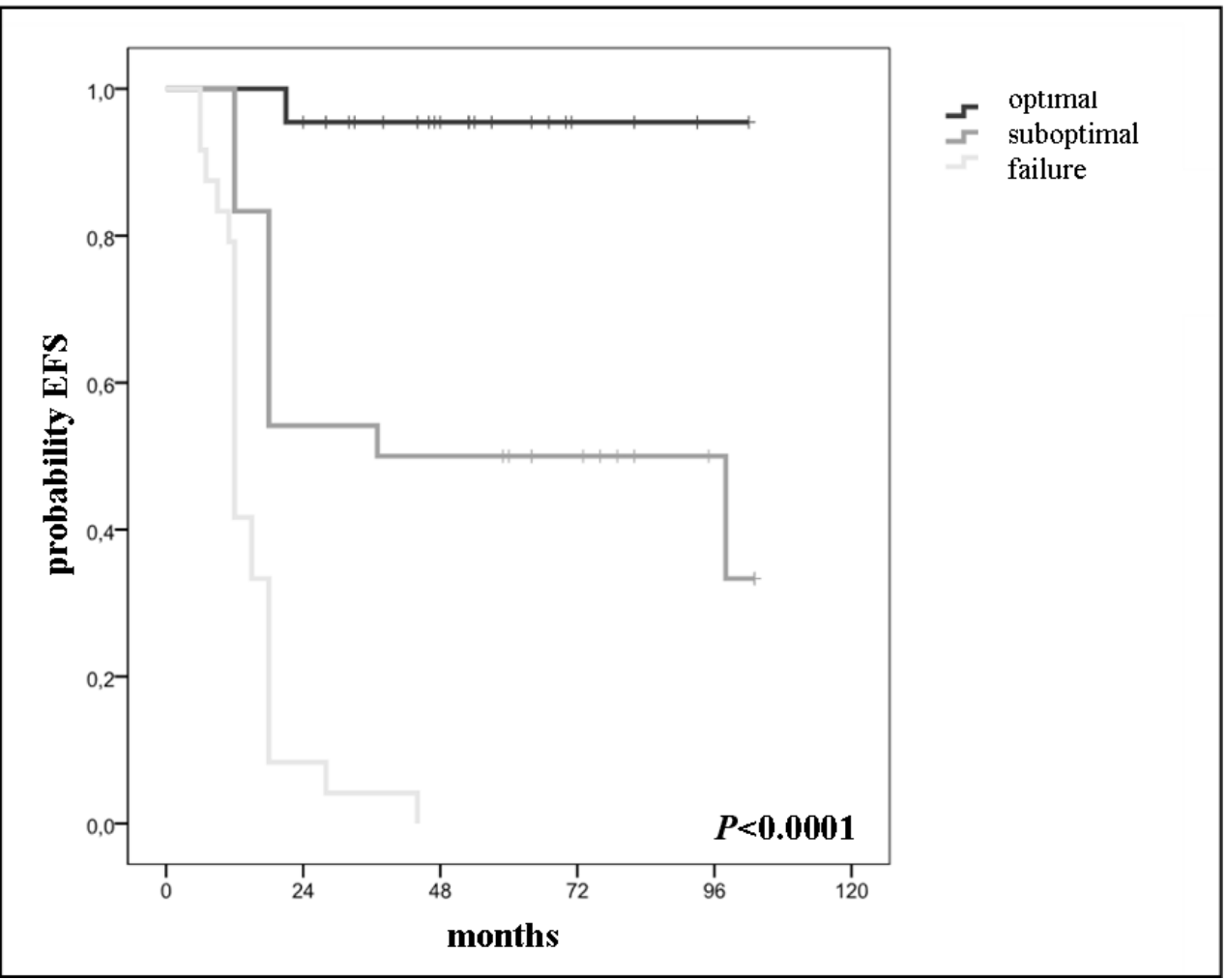

Fig. 3a. Event-free survival in CML patients according to ELN criteria (IFN- $\alpha$ pretreatment).

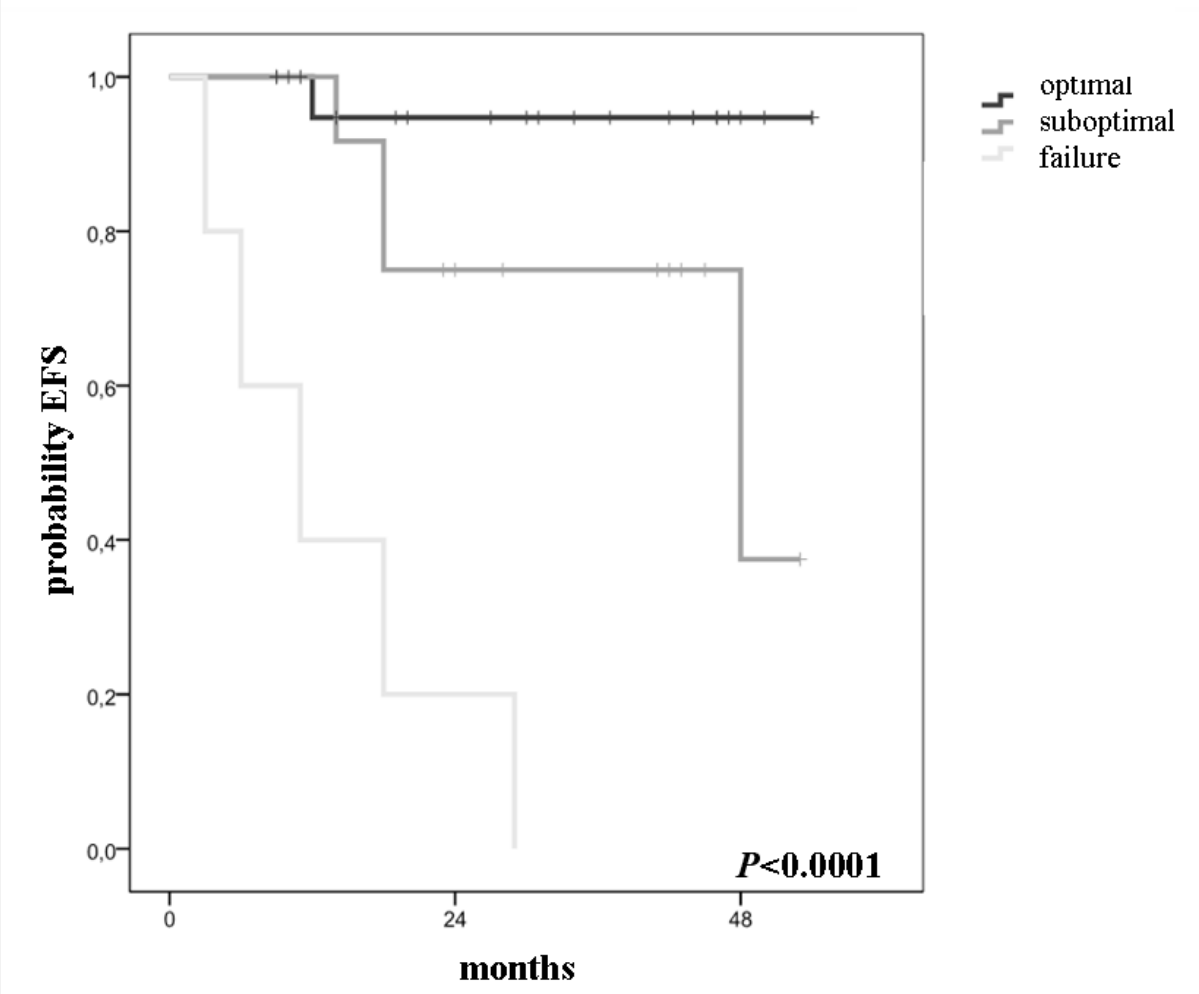

Fig. 3b. Event-free survival in CML patients according to ELN criteria (IMA $1^{\text {st }}$ line therapy).

and standard dosage of IMA. The provisional guidelines for management of patients with suboptimal response are outlined in (Fig. 4).

Due to the small number of patients with ACAs it was impossible to statistically analyze their impact on OS. However, the published data suggest that there is probably no difference in survival between individuals with a single abnormality (Ph chromosome) and those with ACAs such as $\operatorname{der}(9 q)$ deletion or chromosome 8 trisomy, i.e. almost all abnormalities seen in our group. Identification of a complex karyotype is a completely different case ${ }^{22}$.

At present, interim criteria are available for assessing treatment with second-generation TKIs in chronic-phase CML patients resistant to IMA. These are more restrictive - suboptimal response: minCyR at 3 months, PCyR at 6 months, no MMR at 12 months; failure: noCyR at 


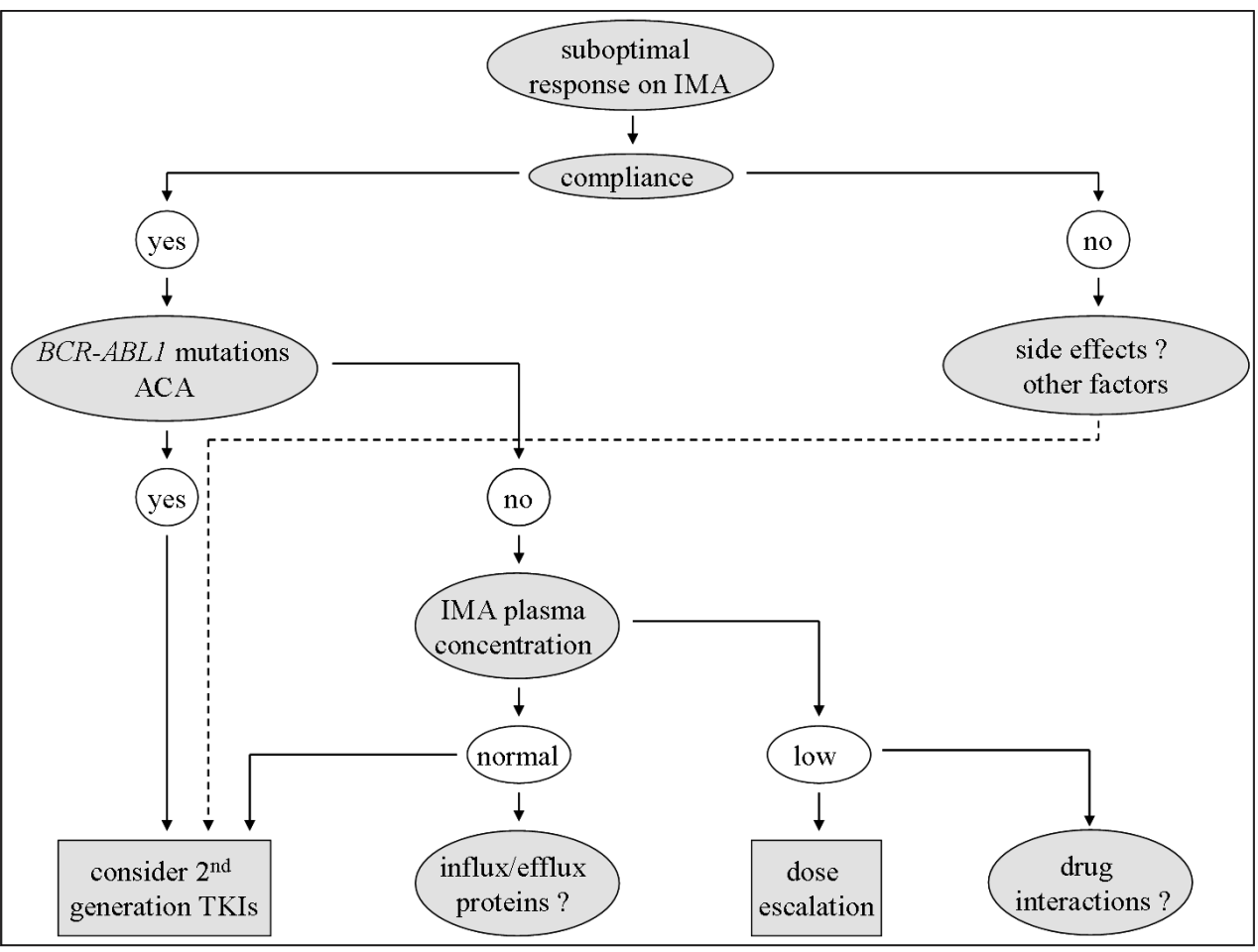

Fig. 4. Suboptimal response to IMA treatment review of basic mechanisms and therapeutic options $\left(\right.$ modified from $\left.^{26}\right)$. months, minCyR at 6 months, no PCyR at 12 months) (ref. $\left.{ }^{2}\right)$.

The present study analyzed a group of chronic-phase CML patients treated in Olomouc, Czech Republic. The ELN criteria have an independent prognostic value for the OS, PFS and EFS but the future will necessitate revision,especially in regard to the category of suboptimal response.

\section{ABBREVIATIONS}

ACAs, Additional chromosome abnormalities; CCyR, Complete cytogenetic response (Ph-positive metaphases undetected); CHR, Complete hematologic response (normal blood count values - WBC count $<10 \times 10^{9} / \mathrm{L}$, less than $5 \%$ of basophils, normal differential WBC count without immature granulocytes, platelet count < 450x10 $/ \mathrm{L}$, nonpalpable spleen); CML, Chronic myeloid leukemia; CP, Chronic phase; CyR, Cytogenetic response; Dg., Diagnosis; EFS, Event-free survival; ELN, European LeukemiaNet; HSCT, Hematopoietic stem cell transplantation; HU, Hydroxyurea; IFN- $\alpha$, Interferon-alpha; IMA, Imatinib mesylate; IRIS, International Randomized Study of Interferon vs STI571; MCyR, Major cytogenetic response; minCyR, Minimal cytogenetic response (reduction of Ph-positive metaphases to 66\%); MMR, Major molecular response $\mathrm{BCR} / \mathrm{ABL}$ to $\mathrm{ABL}$ ratio $\leq 0.1 \%$ of the international scale ; OS, Overall survival; PCyR, Partial cytogenetic response (Ph-positive metaphases 1-35\%); PFS, progression-free survival; $\mathrm{Ph}$, Philadelphia chromosome; TKIs, Tyrosine kinase inhibitors;WBC, white blood cell
Table 3. Analysis of resistance to IMA treatment ${ }^{13-24}$.

- Leukemic cell

○ BCR-ABL1-dependent

$\checkmark$ amplification of $B C R-A B L 1$ gene

$\checkmark$ mutations in $B C R-A B L 1$ gene

○ $B C R$ - $A B L$ 1-non-dependent

$\checkmark$ constitutive activation of other signaling molecules (e.g. SRC kinases)

$\checkmark$ multi-drug resistance (MDR-1)

$\checkmark$ changes in cellular efflux/influx pumps

$\checkmark$ additional cytogenetic abnormalities in $\mathrm{Ph}$ positive clone

- Extracellular

$\checkmark$ immunologic factors

$\checkmark \alpha 1$-acid glycoprotein

$\checkmark$ low IMA plasma level

\section{ACKNOWLEDGEMENT}

This research was supported by the Ministry of Health of the Czech Republic (grant NT12218), by student project LF_2011_006 of Palacky University and by University Hospital Olomouc. We would like to thank the personnel at the Laboratory of Cytogenetics and at the Laboratory of Molecular Genetics at the Department of HematoOncology for their expert technical assistance. 


\section{REFERENCES}

1. Baccarani M, Saglio G, Goldman J, Hochhaus A, Simonsson B, Appelbaum F, Apperley J, Cervantes F, Cortes J, Deininger M, Gratwohl A, Guilhot F, Horowitz M, Hughes T, Kantarjian H, Larson R, Niederwieser D, Silver R, Hehlmann R. Evolving concepts in the management of chronic myeloid leukemia: recommendations from an expert panel on behalf of the European LeukemiaNet. Blood 2006;108:1809-20.

2. Baccarani M, Cortes J, Pane F, Niederwieser D, Saglio G, Apperley J, Cervantes F, Deininger M, Gratwohl A, Guilhot F, Hochhaus A Horowitz M, Hughes T, Kantarjian H, Larson R, Radich J, Simonsson B, Silver RT, Goldman J, Hehlmann R. Chronic myeloid leukemia: an update of concepts and management recommendations of European Leukemia Net. J Clin Oncol 2009;27:1-11.

3. Marin D, Milojkovic D, Olavarria E, Khorashad JS, de Lavallade H, Reid AG, Foroni L, Rezvani K, Bua M, Dazzi F, Pavlu J, Klammer M, Kaeda1 JS, Goldman J, Apperley J. European LeukemiaNet criteria for failure or suboptimal response reliably identify patients with CML in early chronic phase treated with imatinib whose eventual outcome is poor. Blood 2008;112:4437-44.

4. Faber E, Nausova J, Jarosova M, Egorin MJ, Holzerova M, Rozmanova S, Maresova I, Divoky V, Indrak K. Intermittent dosage of imatinib mesylate in CML patients with history of significant hematologic toxicity after standard dosing. Leuk Lymphoma 2006,47:1082-90.

5. de Lavallade H, Apperley J, Khorashad JS, Milojkovic D, Reid AG, Bua M, Szydlo R, Olavarria E, Kaeda J, Goldman JM, Marin D. Imatinib for newly diagnosed patients with chronic myeloid leukemia: incidence of sustained responses in an intention-to-treat analysis. JCO 2008;20:3358-63.

6. National Comprehensive Cancer Network. Clinical Practice Guidelines in Oncology: chronic myelogenous leukemia,V.1.2009, www.nccn.org/professionals/physician_gls/PDF/cml.pdf

7. Hochhaus A, Dreyling M. Chronic myelogenous leukemia: ESMO clinical recommendations for the diagnosis, treatment and followup. Ann. Oncol. 2008;19:63-4.

8. Australasian Leukemia and Lymphoma Group (ALLG). Myeloproliferative Disease Subcommittee. Australasian treatment guidelines for de novo CML CP, v1.0. Canterbury Health Laboratories, Christchurch, New Zealand 2006.

9. Laneuville P, Barnett MJ, Belanger R, Couban S, Forrest DL, Roy DC Lipton JH. Recommendations of the Canadian Consensus Group on the Management of Chronic Myeloid Leukemia. Curr. Oncol. 2006;13:201-21.

10. Deininger M, O'Brien SG, Guilhot F, Goldman JM, Hochhaus A Hughes TP, Radich JP, Hatfield AK, Mone M, Filian J, Reynolds J, Gathmann I, Larson RA, Druker BJ. International randomized study of interferon vs STI571 (IRIS) 8-year follow up: sustained survival and low risk for progression or events in patients with newly diagnosed chronic myeloid leukemia in chronic phase (CML-CP) treated with imatinib. Blood 2009;114:482, Abstract 1126.

11. Druker BJ, Guilhot F, O'Brien SG, Gathmann I, Kantarjian H, Gattermann N, Deininger MWN, Silver RT, Goldman JM, Stone RM, Cervantes F, Hochhaus A, Powell BL, Gabrilove JL, Rousselot P, Reiffers J, Cornelissen JJ, Hughes T, Agis H, Fischer T, Verhoef G, Shepherd J, Saglio G, Gratwohl A, Nielsen JL, Radich JP, Simonsson B, Taylor K, Baccarani M, So C, Letvak, L, Larson RA. Five-year follow-up of patients receiving imatinib for chronic myeloid leukemia. $\mathrm{N}$ Engl J Med 2006;355:2408-17.

12. Hughes TP, Kaeda J, Branford S, Rudzki Z, Hochhaus A, Hensley ML, Gathmann I, Bolton AE, van Hoomissen IC, Goldman JM, Radich JP.
Frequency of major molecular responses to imatinib or interferon alfa plus cytarabine in newly diagnosed chronic myeloid leukemia. N Engl J Med. 2003;349:1423-32.

13. Tipping AJ, Mahon FX, Lagarde V, Goldman JM, Melo JV. Restoration of sensitivity to STI571 in STI571- resistant chronic myeloid leukemia cells. Blood 2001;98:3864-7.

14. Branford S, Rudzki Z, Walsh S, Parkinson I, Grigg A, Szer J, Taylor K, Herrmann R, Seymour JF, Arthur C, Joske D, Lynch K, Hughes T. Detection of $B C R / A B L$ mutations in patients with CML treated with imatinib is virtually allways accompanied by clinical resistance, and mutation in the ATP-phosphate binding loop (P-loop) are associated with a poor prognosis. Blood 2003;102:276-83.

15. Tauchi T, Ohyashiki K. Molecular mechanism of resistance of leukemia to imatinib mesylate. Leuk Research 2004;28:39-45.

16. Donato NJ, Wu JY, Stapley J, Gallick G, Lin H, Arlinghaus R, Talpaz M. $B C R-A B L$ independence and LYN kinase overexpression in chronic myelogenous leukemia cells selected for resistance to STI571. Blood 2003;101:690-8.

17. Hamada $A$, Miyano $H$, Watanabe $H$, Saito $H$. Interaction of imatinibe mesylate with human P-glycoprotein. Journal Pharmacol Exp Ther 2003;307:824-8.

18. Widmer N, Colombo S, Buclin T, Decosterd LA. Functional consequuence of MDR1 expression on imatinib intracellular concetrations. Blood 2003;102:1142.

19. Thomas J, Wang L, Clark RE, Pirmohamed M. Active transport of imatinib into and out of cells: implications for drug resistance. Blood 2004; 104:3739-45.

20. Burger $\mathrm{H}$, Nooter K. Pharmacokinetic resistance to imatinib mesylate: role of the $A B C$ drug pumps $A B C G 2$ (BCRP) and $A B C B 1$ (MDR1) in the oral bioavailability of imatinib. Cell Cycle 2004;3:1502-05.

21. Terre C, Eclache V, Rousselot P, Imbert M, Charrin C, Gervais C, Mozziconacci MJ, Maarek O, Mossafa H, Auger N, Dastugue N, Talmant P, Van den Akker J, Leonard C, N'Guyen Khac F, Mugneret F, Viguié F, Lafage-Pochitaloff M, Bastie JN, Roux GL, Nicolini F, Maloisel F, Vey N, Laurent G, Recher C, Vigier M, Yacouben Y, Giraudier S, Vernant JP, Salles B, Roussi J, Castaigne S, Leymarie V, Flandrin G, Lessard M. Report of 34 patients with clonal chromosomal abnormalities in Philadelphia-negative cells during imatinib treatment of Philadelphia-positive chronic myeloid leukemia. Leukemia 2004;18:1340-46.

22. Holzerova M, Faber E, Veselovska J, Urbankova H, Balcarková J, Rozmanová S, Voglova J, Muzik J, Chroust K, Indrak K, Jarosova M. Imatinib mesylate efficacy in 72 previously treated Philadelphiapositive chronic myeloid leukemia patients with and without additional chromosomal changes: single centre results. Cancer Genetics and Cytogenetics 2009;191:1-9.

23. Mustjoki S, Lundan T, Knuutila S, Porkka K. Appearance of bone marrow lymphocytosis predicts an optimal response to imatinib therapy in patients with chronic myeloid leukemia. Leukemia 2007;21:2363-8.

24. Gambacorti-Passerini C, Barni R, Le CP, Zucchetti M, Cabrita G, Cleris L, Rossi F, Gianazza E, Brueggen J, Cozens R, Pioltelli P, Pogliani E, Corneo G, Formelli F, D'Incalci M. Role of alpha1 acid glycoprotein in the in vivo resistence of human $B C R-A B L(+)$ leukemic cells to the ABL inhibitor STI571. J Natl Cancor Inst 2000;92:1641-50.

25. García-Gutiérrez V, Herrera $P$, Jimenez-Rolando $P$, Tenorio $M$, Calbacho M, Velasco D, Alonso JM, Ramos L, Ramos P, Rey MD, López-Jiménez J.Outcomes of chronic myeloid leukemia patients with suboptimal response to imatinib. EHA 2011, poster No. 0696.

26. Porkka K, Mustjoki S, Simonsson B. Suboptimal responses in chronic myeloid leukemia: milestones and mechanisms. Expert Rev Hematol. 2009;1:81-91. 